\title{
Mobility-as-a-service (MaaS) digital marketplace impact on EU passengers' rights
}

\author{
Erion Murati®D
}

\begin{abstract}
Integrated and seamless mobility has been a futuristic vision of mobility for a few years already. Today, Mobility as a Service (MaaS) embodies that vision through the integration of existing and new mobility services into one single digital platform, providing customised door-to-door transport and offering personalised trip or packages planning and payment options. The MaaS concept enable a practical shift from a fragmented and unimodal transport towards a harmonized, centralized and multimodal one, yet the current EU transport law, which is based on the principle of unimodality transport regulation, does not cover any passenger multimodal transport. Thus, as MaaS providers generate multimodal travel chains, it's problematic that under EU law there is no harmonised legal base for multimodal passenger travel. Moreover, passenger rights cannot be guaranteed when an event occurring during one transport segment affects the following one, if the latter segment is operated with another operator of transport. In light of this, the knowledge gaps that this paper aims to fulfil are to comprehend, on the one hand, the status quo of EU passenger legislation and, on the other hand, the impact of MaaS concept on EU passenger's rights. This will be achieved by analysing the EU transport law and its adequacy to cover passenger's rights through a MaaS multimodal journey, as well as the position of a MaaS provider in a travel chain.
\end{abstract}

Keywords: MaaS, Passengers' rights, Multimodal contract, Transport platforms, Online marketplaces

\section{Introduction}

Recently the passenger transport industry has been disrupted by the emergence of online platforms - i.e. Uber and BlaBlaCar - relying on the sharing of a specific asset (i.e. a vehicle) or of a dedicated service (i.e. a ride), and mediating between new transport service providers, often non-professional service providers, and passengers. Factors driving transportation app growth include: time savings, financial savings and incentives ([1], p. 150). For public agencies [2], and traditional transport services ([3], p.122), transportation apps can aid network management functions, such as disseminating roadway and public transportation information on incidents, delays and congestion and improving integrated mobility

Correspondence: erion.murati@studium.uni-hamburg.de

MaaS project, Faculty of Law, University of Hamburg, Hamburg, Germany payment schemes. For mobility users ([2], p. 7), the purpose of these apps is to facilitate door-to-door mobility by giving people greater control over their trips, through "real-time" access information and coordination, previously unavailable. However, according to Montero [4], transport platforms pose very significant regulatory challenges as to the role of platforms from a legal perspective and passengers' rights.

Passenger transport services have failed to ensure a uniform supply for all, mainly for two reasons: first, the complexity of using a variety of transport modes with different payment methods; second, a lack of integrated information and payment methods, ensuring seamless and multimodal trips. This paper argues that the key to solving many transportation issues is the integration, offered by the MaaS concept, of existing and new mobility 
services through one single digital platform. The MaaS concept was officially introduced to the public at the 2014 Intelligent Transport Systems (ITS) European congress in Helsinki during a video ${ }^{1}$ demonstration entitled "Could Mobility be viewed as Service?". In 2016, the EU HORIZON 2020 call financed the MaaS4EU ${ }^{2}$ project in order to stimulate European development towards MaaS with a total budget of 25 million Euros. In the meantime, Sweden and Finland (recently also Germany, France and Netherlands) have acted as pioneers in the development of the MaaS concept. For instance, the 2014 pilot of UbiGo in Gothenburg is often referred to as the first demonstration of the MaaS in real-life conditions, whilst the 2016 launch of Whim in Helsinki (FI) drew international attention to the concept of the MaaS ([5], p. 2).

For the purpose of this paper it is sufficient to underline the lack of a single and uniform definition of MaaS, mainly due to the novelty of the concept itself and because of the different perspectives under which MaaS could be understood (i.e. economic, technological, legal, etc).

According to the godfather of the MaaS concept, Sampo Hietanen, MaaS is "a co-operative, interconnected ecosystem, providing mobility services reflecting the needs of customers, met over one interface and are offered by a service provider bundled into a package - similar to mobile phone price-plan packages" [6]. While according to Utriainen's and Pöllänen's literature review on MaaS ([7], p. 152), MaaS is defined as "a concept in which individual's mobility needs can be fulfilled effectively and more sustainably than currently by integrating different transport modes and services to seamless journeys". Otherwise, in their recent literature review on MaaS, Molinares and Polinares [8], due to the various definitions that could be found on MaaS, hesitate to give a definition. Instead, they highlight its core elements: a unique single platform (app or website), real-time information on all available modes in the city (public and private), multimodal transportation (intermodal journey planners), technological integration to plan, book and pay for mobility needs, and personalized bundled mobility packages according to a user's particular requirements.

Subsequently, one recurring topic in literature is the identification of all actors involved in the service, known as the MaaS Ecosystem [9]. The MaaS concept introduces new roles in the value chain. According to Kamargianni and Matyas [10], this new player is the MaaS Provider who has to enter the transport market in order to realize MaaS. Otherwise, [11], p. 593) argued that the development of MaaS introduces a need for two new

\footnotetext{
${ }^{1}$ See 'Could Mobility be viewed as Service', available in YouTube https://www.youtube.com/watch?v=ZQieTU7_5xo Accessed 12 June 2020

${ }^{2}$ See http://www.maas4eu.eu/ Accessed 12 June 2020
}

roles in the value chain: (a) MaaS Integrators that assemble the offerings of several transport service providers to MaaS Operators through activities such as technical integration and (b) MaaS Operators that package and deliver MaaS to end-users by enabling them to seamlessly plan, pay for and execute use of public transport and other transport services, through a single interface. Accordingly, it is unclear whether the public, private or both sectors should adopt these roles, which created significant inter-organizational tension ([12], p. 58). In any case, these debates are concerned with the back-end side (also called the data platform or data layer) where the MaaS provider (or operator) operates via integration of data such as routes, pricing information or real-time position. Therefore, object of analysis here is the so-called front-end side, or the app (i.e., Whim app, Jelbi app, etc.) which is the major customer interface and is connected to the back-end.

Acknowledging the state of affairs described above, the MaaS definition adopted in this paper comes from the MaaSiFiE project ([13], p. 7), namely "Multimodal and sustainable mobility services addressing customers' transport needs by integrating planning and payment on a one-stop-shop principle".

Essentially there are two main reasons for the adoption of this definition. First, that definition underlines the term of "one-stop-shop principle". Thus, for the purpose of this work MaaS is about offering a digital mobility marketplace to passengers. Online marketplaces, like physical stores, play a dual role: they are "places" where consumers can purchase goods and services, but they also provide information to consumers about the availability and characteristics of goods. In light of this, a MaaS provider effectively runs a mobility search engine: users search for a mobility means and MaaS provider returns results, suggesting the cheapest, fastest, most reliable or most ecological route to get from A to B while at the same time seeking to optimise its own revenue (or other goals). Passengers are free to choose and pay on the MaaS digital marketplace' buy box either MaaS Operator offerings either transport providers tickets or a combination thereof. This digital mobility marketplace (similar to other online marketplaces such as Amazon) is the main added value of MaaS for customers. However, MaaS platforms will influence, if not determine, consumer choices [14] and not always in their interest (i.e., price discrimination). In a nutshell, MaaS platforms allow the supply side (the suppliers) to meet the demand side (the customers), shaping a (triangular structure) digital mobility marketplace. From a legal perspective, this new mobility digital marketplace is the fundamental aspect of the MaaS concept.

Second, that definition highlights also two important terms: "multimodal and sustainable". MaaS is multimodal 
by nature. To meet a customer's request, a MaaS provider facilitates a diverse menu of transport options, be they public transport, car, bike or scooter sharing, taxi, car rental or lease, or a combination thereof, accessible on demand. The MaaS concept is about shifting from a fragmented and unimodal transport towards a harmonized and multimodal market ecosystem, which relies heavily upon new technologies to facilitate both individual and collective mobility. Multimodal passenger transportation enables sustainable and efficient travel within cities and allows passengers to be connected to public transportation from the first to the last mile. The combination of these new technologies allows a mobility which is in no way inferior to the freedom promised by a private car. Indeed, recent research [15] shows that the more multimodal-minded individuals were, the more likely they were to decrease their car use and increase the shift towards the use of green modes of transport. Furthermore, according to EU Commission communication a 'European strategy for low-mission mobility' ([16, 17], p. 4) multimodality is often praised for, on the one hand, improving the efficiency of the whole transport system, promoting the best use of each mode, and, on the other hand, contributing to vehicles' low emission through making more efficient use of the existing vehicle fleet and increasing vehicle occupancy.

However, the MaaS multimodality does not fit quite well under the current EU unimodal transport regulation. From a strict legal perspective, multimodal travel suffers a fragmented EU legal base. First, to each transport means specific rules based on different legal sources (national or EU laws) apply, with multimodal travel chains not being covered by any legislation (no rules on rerouting or assisting when transferring between modes), unless the Package Travel Directive (EU) 2015/2302 (hereafter PTD) or national passenger multimodal legislation applies. Second, there are no common rules on compensation and damages, and passengers' rights and carriers' liabilities vary between transport modes and applicable law. The perceived problem is that one service provider in a multimodal journey does not know who is providing the next leg of the trip, as there is no contract between the two. Yet, for the MaaS to be beneficial to passengers, someone should make sure the travel chain remains unbroken. Thus, the rebus is to understand whether, how and who is going to assume this position in a multimodal chain from a legal perspective. As it is shown in the next sections, the answer to this would mainly depend on the legal status of the MaaS provider condition in MaaS schemes integration and/or from the type of the multimodal contract offered to the users by a MaaS Operator (i.e., separate vs. single multimodal contract). Therefore, through this article it will be analysed the impact of the multimodality element, embodied by the MaaS concept, on EU passenger transport law and passenger's rights.

In section two the current typologies of multimodality are discussed, whilst section three assesses the broadlyunderstood European passenger legislation, and in section four the possible roles of a MaaS provider are presented. In section 5 a multimodal chain is analysed in detail through examples and related legal implications.

\section{MaaS and current typologies of passenger multimodal transport}

As a general principle, it is important to remember that MaaS is multimodal by nature and the EU Green Deal ([18], p. 10) defines MaaS and its multimodality as one of the key challenges for the future of European mobility and connectivity. The principle of unimodality underlines that for each transport mode there exist separate legal instruments dealing with the passengers' rights and carrier's liability. Therefore, from a historic perspective passenger multimodal transport is a new phenomenon compared to multimodal transport for carriage of goods which, in turn, has a long tradition. The later, according to Finger and Audoin ([19], p. 5), has been enabled by the development of integrated multimodal information systems and integrated payment solutions. While the former, according to Hoeks [20], emphasizes the following elements. First, multimodal transport for the carriage of goods is defined as carriage consisting of at least two different modes of transport. Second, the carriage should be based on one single contract between a multimodal carrier and a shipper; however subcontracting becomes essential. Finally, a multimodal transport carrier (MTC) acts as a principal and assumes responsibility for the whole performance of the contract.

From a passenger multimodal transport perspective, Brunagel et al. [21] distinguishes five typologies of passenger multimodal mobility contracts.

I) There are three sub-categories of multimodal transport operating under separate contracts: a) separate contracts between the passenger and carriers, combined as a multimodal journey at the passenger's own initiative (typology 1); b) separate contracts between the passenger and carriers resulting from an agreement between two or several carriers to offer a multimodal product (typology 2); c) and separate contracts between the passenger and carriers but being offered to the passenger via an intermediate entity (typology 3). II) There are two sub-categories of multimodal transport operating under a single contract: a) single contract resulting from an agreement between two or several carriers to offer a multimodal product, in which one of the carriers acts as the single contracting party towards the passenger. In such a case, provisions regarding liability-sharing are included in the agreement between the carriers concerned 
(typology 4); Typical examples are rail-air intermodal agreements ${ }^{3}$ which, however, may rise competitions concerns ([22], p. 28) as it is ascertained that air and highspeed rail transport services can, on short to medium distances itineraries, belong to the same market and amount to substitute services; b) single contract consisting of a product offered by an intermediate entity (i.e. an online seller or a tour operator), which includes transport services by all carriers involved. The passenger concludes a transport contract with the intermediate. Following the Eurobarometer ([23], p. 111-113), only $11 \%$ of respondents have used a single multimodal transport ticket in the last 12 months, with rail and coach being the most common combination (30\%), followed by rail air (24\%) and air and coach (14\%). In a MaaS context, the third typology of multimodal context corresponds to MaaS level two and three of transport integration ([24], p. 193) where users can find, book, and pay for their trip at a single service (app) point and be charged a commission by the operator. Otherwise, the fifth typology of multimodal context corresponds to MaaS level four [25] of transport integration where align full integration and mobility incentives towards users. Therefore, inter alia, it seems that both the concepts of multimodality share the same structural characteristic: two or more carriers (and transport means), one single contract and one multimodal transport operator (i.e., the MaaS provider or the MTC). Further, either the passenger multimodal or the multimodal for the carriage of goods, [20] suffer from the legal fragmentation and lack of harmonization in their related industry.

\section{EU vacatio legis on passenger multimodal transport}

Cities are the first places where MaaS is being implemented ([26], p. 117) due to the high population, the existence of transportation infrastructure and transport modes. Consequently, this paper illustrates European legal rules pertaining to train and bus travel. Nevertheless, the air passenger rights are examined as well, for the following two reasons. First, MaaS on national and EU levels is usually related to long-haul travel either for work or leisure purposes. In that case, air traffic becomes an essential component of the MaaS service (D [13], p. 57). Indeed, several airline companies, such as Lufthansa, as well as railways (i.e DB, RENFE,) offer the air-rail transport combination. The total multimodal market is estimated at approximately 65.7 million passengers in 2016, out of a total of 10.6 billion passengers carried in the EU by air and rail, on a yearly basis. The

\footnotetext{
${ }^{3}$ From a systematic standpoint, three types of agreements may be identified, namely: a) air-rail interlining; b) air-rail code sharing; c) airrail global alliance programmes.
}

passenger air-rail market segment represents $65 \%$ of the multimodal market (around 43 million passengers) and around $7 \%$ of total international air traffic in the EU ([21], p. 10). Second, the European Commission intends to amend the air passenger rights Regulation (EC) No 261/2004, (hereafter air Regulation) proposing also a solution in case of transport disruption in a multimodal transport contract [27].

Subsequently, the European Union is the only area in the world where passengers are protected by a full set of a passenger rights when they travel by air (air Regulation 261/2004), train (rail Regulation 1371/2007), ship (sea Regulation 1177/2010) and coach (bus and coach Regulation 181/2011). They are based on three cornerstones: non-discrimination; accurate, timely and accessible information; immediate and proportionate assistance ([28], p. 219). The legislation enshrines rights relating to information about the journey, reservation, fares, and damages to luggage, as well as accidents, delays and cancellations or denied boarding. Rules are also set up for compensation, re-routing, reimbursement of tickets costs and assistance such as meals or accommodation. In addition, specific rights exist for those with disabilities or reduced mobility. According to the European Court Auditors [29], passenger rights are comprehensive, but passengers still need to fight for them. Although these sets of rights exist in all the four modes of transport still substantial differences exist between them in the rights of passenger in case of disruptions, assistance or carrier's liabilities (Brunagel et al., p. 50). There are also numerous international unimodal transport agreements dealing with the carriage of passengers (i.e., the 1999 Montreal Convention for the air transport or the 2002 Athens Convention for the sea transport) which predominantly regulate rights related to the compensation by the carrier in case of death of or personal injury to a passenger, right to compensation for the lost or damaged baggage as well as the right related to compensation in case of a delayed transport ([30], p. 201).

The initiatives to address passenger rights in multimodal transport fall under the EU's transport policy. Indeed, the EU Commission considered 2018 as the year of multimodality and different initiative has been taking place. In its Communication on passenger rights in all transport modes [31], the Commission acknowledged that, as multimodal transport becomes a reality through, for example, the integration of carrier contracts, the legislative framework for passenger rights will need to be adapted to tackle the issue of disruption at connecting points in a multimodal journey. The problem was also underlined by the EU Commission in its Interpretative Guidelines on the rail Regulation [32] and on the air Regulations ([17], p. 5) where it recognised, again, that currently problems arising from the use of more than 
one mode of transport are not covered under any EU legislation on passengers' rights.

According to Brunagel et al., ([21], p. 10) the perceived problems are that in a multimodal context passengers' rights are mostly based on contractual terms, with a number of legal gaps or "grey zones" which are currently not covered by the European transport regulations (connecting points, transfers etc). First, if as a result of a transport disruption in the context of a single contract of carriage, the passenger misses the connecting service provided by another mode of transport, his or her rights are not adequately protected. For instance, if the passengers miss a flight because of a train service delayed, they will only benefit from the right to compensation and assistance granted in relation to train service, and then only if they were delayed more than $60 \mathrm{~min}$. This issue is also confirmed by the 2019 special Eurobarometer (hereafter Eurobarometer) on passenger's rights ([23], p. $116)$, where a quarter $(25 \%)$ of respondents did experience problems with multimodal tickets. The most common is almost missing a connection due to a delay or cancellation (9\%), while $8 \%$ actually missed a connection for this reason. Second, the passengers cannot seek redress from the national authorities bodies (NEBs') which are responsible for enforcing the existing passenger rights regulations because those authorities do not have a legal basis to deal with complaints related to multimodal journeys on the basis of the existing passenger rights legislation. Third, transport operator's liabilities are mode-specific as regards passenger rights, meaning that, in the absence of harmonised clauses and standards liability agreements, it's impossible to establish their responsibility, notably in case of travel disruption but not only. Finally, assistance and information are not guaranteed, especially for passengers with disabilities using multimodal products at the connecting points: on the basis of the current modal passenger right EU legislation, carriers are only obliged to provide assistance in relation with their own modal services, but not during the multimodal connection. On many occasions, passengers are not informed about who they should complain to if something during their trip goes wrong ([33], p. 3).

To sum up, as a matter of fact, there is a legal vacuum at the level of EU only regarding the passenger protection when travelling multimodal. Accordingly, the next question is to understand the extension of this vacuum, seeking to comprehend the application of other legal instruments by systematic legal interpretation. For instance, in their study Brunagel et al. [21] did not mention cases where PTD applies to passengers' rights in a multimodal contract if the multimodal journey is combined with another travel service (i.e. accommodation/car rental). If so, the main current problems of travelling multimodal such as no specific rules on rerouting, missed connection or assisting when transferring between modes will be covered by this Directive. Thus, the passengers will be protected from any disruption occurring in this context. In addition, there may be also cases where national multimodal passenger legislation applies. Very good examples of this are articles 656 and 657 of Croatian Code (1994) which prescribe the protection of passenger's rights in multimodal contracts. These mentioned legislations could be stretched to cover also MaaS passenger multimodal offers if all the required conditions were met (see sect. 4).

\section{Possible legal status of the MaaS provider}

Passenger rights and carrier liabilities are mainly determined by the specific regulation on each mean of transport - regardless of whether the passenger has purchased the ticket from a MaaS provider or the passenger carrier itself. The EU legislation applicable to multimodal transport depends considerably on the position and role of each party into the travel chain Thus, the legal status of a MaaS provider does not come directly from the above EU regulations, but depends on the scope of the service provided, the role of the passenger and the mutual contractual relations of the parties. Importantly, by 'legal status' this paper refers to the whole relevant system of law which regulates, on the one hand, the official position or condition of a MaaS platform provider itself, and, on the other hand, his relationship, respectively, with mobility providers and passengers. Usually, most of the online platforms prefer to claim to act only as an intermediary because of the EU single market benefits ${ }^{4}$ offered by the E-Commerce Directive (EC) 2000/31 (hereafter ECD) to information society services. However, this self-classification has been challenged by traditional service operators, accusing platforms for unfair competition (i.e. operating without the required license and without meeting other regulatory obligations for offering access to the material services). In the case of 'Elite Tax v. UberPOP' (2017) and 'Airbnb Ireland v. ATHOP' (2019) this conflict became evident. The Court of Justice of the European Union (CJEU) ruled that UberPop intermediation service as not "an information society service" but as "a service in the field of transport", while Airbnb Ireland platform constitutes an "information society service" and "not accommodation service". Both cases related to the problem of the classification of services

\footnotetext{
4 a) the electronic intermediary service will benefit from the principle of freedom to provide services as guaranteed in EU legislation Article 56 TFEU and Directives [2006/123] and [2000/31]; b) they cannot be held responsible for any ill-execution of the underlying contract (service) or for damage accruing therefrom under art. $3 \mathrm{E}$ commerce directive; and c) they can claim to be fully absolved from any liability, including for misrepresentation, offensive or illegal content, under Articles 13,14. 15 of the E-Commerce Directive.
} 
provided via electronic platforms, however, the CJEU decided differently on the ground that while UberPop exercised decisive influence under the provision of the material service (i.e., fixing prices) Airbnb did not. Therefore, on MaaS ecosystem, depending on the actual circumstances of each case and how MaaS services are markets to consumers, a MaaS provider may have one of the following (hypothetical) legal roles:

(a) A comprehensive service provider, (rather a multimodal transport operator) ([34], p. 3) which acts as a principal and is responsible towards passengers for ensuring that transport in the travel chain or replacement transport is carried out. Here the platform delivers the digital and the underlying service and plays a predominant role in the defining and/or delivering of the material service. The passenger will have a direct contractual relationship with the MaaS provider which will use independent passenger carriers to assist itself in the performance of the contract (subcontractors) being responsible for their performance as it would be for its own. In this case, the consumer, passenger and traveller EU legislation may apply to various aspects of the MaaS relationships.

(b) An intermediary [35], which means it would offer a platform for connecting service providers and customers, mainly regulated by the ECD as an information society service. Here MaaS provider concludes intermediation contracts, on one hand, with the passenger for the digital services, on the other hand, with the transport providers for the promotion and advertisement the said service. A third contract is concluded, for the provision of the underlying service, between the transport carrier and the passenger. An intermediary is not a party to the contract and is not responsible for its performance (Art. 3 ECD).

(c) A ticket vendor, which means under bus and coach regulation (EU) no. 181/2011(hereafter Bus Regulation) 'any intermediary concluding transport contracts on behalf of a carrier; Importantly, if MaaS platforms were found to act as an agents/ ticket vendor of their transport suppliers on the relevant market for the services regarding which the platform facilitates a transaction, then the implication of this finding in EU competition law would be that agreements between these platforms and their suppliers which contain restrictions of competition on the relevant market cannot be scrutinised under the prohibition of anticompetitive agreements due to the "single economic entity" doctrine. The doctrine treats agreements between agents and their principals as taking place within one and the same undertaking, which renders Article 101 TFEU inapplicable following the requirement that the agreement takes place between separate undertakings for the provision to be applicable. This implies that terms which restrict competition on the relevant market by, for example, fixing prices or restricting output, cannot be scrutinised as anticompetitive agreements [36 $]^{5}$ between MaaS platforms and suppliers. Yet, according to Pinar [36] the "single economic entity doctrine" should be (re)interpreted. Where "competitive neutrality" is replaced with "competitive rivalry" (i.e., platform starts competing with its users) between the platform and the suppliers on the relevant market, it is not possible to justify why the platform and suppliers should count as one and the same entity on the relevant market in relation to contracts negotiated/ concluded with third parties. This (re)interpretation fills the "platform gap" by subjecting the agreements of platforms that are not in a competitively neutral position with regard to their suppliers to the full application of the prohibition of anticompetitive agreements.

(d) A travel agent, which means under Bus Regulation 'any intermediary acting on behalf of a passenger for the conclusion of transport contracts.

Subsequently, according to Dittmar and Indrenius [37] whether a travel chain lasting over $24 \mathrm{~h}$ contains a passenger transport service and a rental car (or accommodation service) a MaaS provider may be:

(i) a travel organizer/tour operator, and the travel chain may constitute a package if the MaaS provider combines all travel chain services under the same contract or separate contracts are concluded with service providers for the services of a travel chain, but the services are selected in the course of one booking process at one online shop, or the services are marketed as a travel chain or under a similar title. Here a MaaS provider uses passenger transport service providers as its assistants and is liable for their performance as it is for its own (Art. 2 PTD) According to Art. 3 PTD the main characteristic of the travel package is that "one organiser is liable for the proper performance of all travel services";

\footnotetext{
${ }^{5}$ After studying concepts of agency in different areas of law including competition law, and the relevant terms and conditions of six different platforms - Uber, Amazon Marketplace, eBay, Booking.com, Apple App Store, Airbnb - it has been found that that these platforms are, as a matter of positive law, on balance, agents of their suppliers.
} 
(ii) a provider of a linked travel arrangement, whenever a travel chain does not constitute a package and the traveller enters into separate contracts with the providers of passenger transport and rental services, but the MaaS provider facilitates: (1) the separate selection and separate payment of each travel service by travellers on the occasion of a single contact; (2) the procurement of at least one additional travel service from another trader in a targeted manner, where a contract with the other trader is concluded at the latest $24 \mathrm{~h}$ after the confirmation of the booking of the first travel service (Art. 3). Its obligations are mainly related to communication, but it may also be held liable for booking errors (Art. 21).

Depending on the nature of its operations, the role of a MaaS provider may also be a hybrid between those discussed here. However, the main difference between these typologies are related to their applicable legal regime, to users' rights and MaaS provider's liabilities. In principle, into the position of intermediary, ticket vendor, travel agent and provider of a linked travel arrangement, MaaS provider does not assume any responsibility for the underperformance/breach of contract of the material service. However, even as an intermediary, MaaS provider may be still liable for the ill performance of the supplier's services if he omits important information regarding this role in the transaction between the user and the supplier. This has been the case of an offline intermediary in the case [38] which had been considered by CJEU as a 'seller' within the meaning of the sale Directive (EC) 98/13. In essence, to avoid the contractual position of a seller/supplier, the MaaS intermediary has to notify the consumer about the fact that it is only acting as an intermediary and give information about the real seller/supplier. If it does not do so, it will be considered a seller/supplier itself with all the legal consequences, including the contractual liability for the quality of the service.

\section{Legal analysis of passenger multimodal transport on MaaS in the macro networks transport integration}

In general, multimodal commercial practice may bring significant benefits to operators and consumers. From a network perspective, MaaS providers, air, bus and rail operators can increase their market presence and share in certain countries and routes. The advantage for consumer seems to be rather evident as they may benefit from inter alia a single reservation, real time information as well as time-saving schedule and increased connection. However, such multimodal transport agreements may rise serious concerns as to the applicable legal framework ([22], p. 27). In light of this, the present section offers an overview of the legal order of each stage in a multimodal chain. The micro transport networks (i.e., urban and suburban transport modes) offer only minimum protection to passengers under national law. This leads to legal uncertainties concerning the allocation of liability among carriers involved in an integrated multimodal journey, in particular when combining micro with macro transport networks (i.e., local transport with longdistance travel). Only this scenario is going to be subject of examination in this section as far as it concerns the application, in different stages, of EU transport law. Further, the legal analysis takes into account the possible legal status of each party and the law applicable for each section in the travel chain, assuming that a MaaS Operator is offering a multimodal transport. The primary need and the right of all passengers is to reach their destination according to the given transport schedule. Thus, it's necessary that a MaaS provider identifies and communicates its role and position in the travel chain so that the passengers know who they are in a contractual relationship with and who provides what.

The following graphic flows according to a logical and practical order. The main assumption is that passenger multimodal (two or more transport modes) travel would take place from point A to point B (Fig. 1). Accordingly, its main elements are then examined in detail from a legal perspective. Importantly, each section of the below graphic is discussing issues pertinent to a unimodal journey in a multimodal transport context, except particular multimodal issues such as missed transport connection.

\subsection{Information and communications duties}

Passengers deserve legal protection on account of their inferior position. To combat market inefficiencies resulting from the information asymmetry that exists between businesses and consumers, an increasing number of mandated information disclosures are imposed on

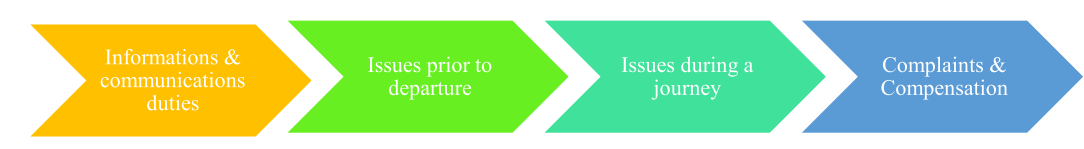

Accessibility \& Data Protection

Fig. 1 Multimodal Passenger Transport from point A to point B 
businesses to give consumers the means to protect their own interests by making autonomous and informed choices ([39], p. 4). However, the legislation on disclosure obligations is fragmented and case-specific, varying between modes of transport and according to the roles of the MaaS operator and the passenger. Information obligations are included in the following: (a) EU specific Regulations on each mean of transport (obligations mainly concern transport carriers, although certain disclosure obligations also apply to the MaaS operator, if it's a comprehensive service provider, a ticket vendor or a travel agent); (b) the Package Travel Directive; (c) ECommerce Directive (EC) 2000/3, regarding in specific MaaS acting as an information society services; (d) the set of provision under consumer rights Directive 2011/ 83/EU (hereafter CRD); In summary, those obligations have an information scope regarding pre-contractual information, prices, terms and conditions of the service, payment methods etc. Consequently, information asymmetries are reduced, and informed consumer choices are taken.

\subsection{Accessibility}

The advancement of smart mobility solutions like MaaS (emphasis added) assumes that citizens have financial, intellectual and physical access to technology and transportation infrastructures. Recent research (Ranchordás, [40]) has shown nonetheless that smart mobility policies often neglect groups of citizens that are affected by transport poverty for numerous reasons (i.e., low income, disabilities or reduced digital literacy). ${ }^{6}$ However, this section by accessibility refers only to the right to access transport infrastructure by people with disabilities (i.e., elderly people, disabled) during the all legs of multimodality. Indeed, amongst the primary rights to which passengers are entitled, such as the right to obtain information, the right to non-discrimination is recognised as being particularly applicable to persons with reduced mobility ([41], p. 89). Specific regulations provide, in different ways, for the obligations of passenger transport carriers to assist disabled passengers and passengers with reduced mobility, if they notify their need for assistance prior to the journey (i.e. Art 9 of Bus Regulation, Art. 11 of Air Regulation, Art. 16 of PTD, Art. 20 and 21 of the new proposal on Rail Regulation etc). These obligations do not apply to a MaaS provider if he is acting in a neutral position, whose primary task is to forward such notifications on the need for assistance to others. In addition, given that the assistance obligations only apply to single modes of transport, passengers with reduced

\footnotetext{
${ }^{6}$ Universal basic mobility (UBM) proponents argue that mobility should be regarded as an essential utility since it is instrumental to gaining access to other essential resources such as food and education.
}

mobility do not, in principle, have a statutory right to assistance when changing from one mode of transport to another when travelling multimodal. Therefore, according to FICORA [34] it is recommended that the MaaS provider and transport carriers agree upon practices in order to transmit information about any assistance given to passengers and the rights of passengers with disabilities in the case of any incidents. However, the fact that passengers are vulnerable ones and that this information is shared among operators poses a threat to their personal data protection.

\subsection{Data protection}

The development of MaaS relies heavily on access to user's data, open Aplication Programming Interface (API) of transport providers and interoperability of the MaaS ecosystems. MaaS is a location-based service (LBS) navigation which uses real-time geo-data from a mobile device to provide user's location and other information. Under Article 4 of the GDPR (EU) 2016/679 location data is expressly mentioned as personal data. LBS becomes crucial in a multimodal travel chain because it helps MaaS provider to issue important information during the all legs of a multimodal chain and/or to re-route passengers in case of a transport disruption to the final destination. Importantly, the data protection right is an external element of multimodal transport and not a structural component of it, such as transport modes and related issues prior/during a journey. Yet, by collecting location data, MaaS providers are able to infer many types of personal information apart from merely location; because many privacy-protected attributes are uniquely associated with places or events, collecting data that show a person who frequently visits a place or attends a particular event represents a powerful means to draw a comprehensive picture of an individual ([42], p. 124). In such cases, location data become sensitive data, such information on the frequency and place of obtaining medical care, religious activities or sex life that require a higher level of protection under Art. 9 GDPR, which in turn it prohibits their processing. Only under specific conditions might such data be processed. Since MaaS providers have to build up a record or database of their customers' personal information they should be treated as the Data Controllers. Further, given that MaaS providers may process sensitive data, then, they also need to handle correctly the adoption of Data Protection Impact Assessment (art. 35 GDPR), which aims to mitigate the risks of data processing activities to data subject rights and freedoms. Therefore, their business must be GDPR compliant. The breach of these obligations may arise fines and liabilities toward the passengers (Art. 82 GDPR). 


\subsection{Issues prior to departure}

Some of the issues prior to departure are lack of information, accessibility, delays and cancellation which do concern all the modes of a passenger multimodal transport. In specific, whenever a part of a travel chain is cancelled or delayed prior to departure, it is important for passengers to be informed of that and how these events of one section of a travel chain affect the rest of it. Delays can occur prior or even during a journey. In rail transport, carriers or a ticket vendor must communicate cancellations and delays (Art. 8 Rail Regulation). Rerouting or a refund of the ticket price must be offered if it is expected that the delay exceeds $60 \mathrm{~min}$. The new proposal for a Regulation of passengers' rights on rail transport (EU) 2017/0237 backs the idea of increasing compensation depending on the length of the delay. However, these rules fail to provide passenger's protection in case of a travel disruption in a multimodal chain. In bus transport, for routes exceeding $250 \mathrm{~km}$, a carrier must communicate a cancellation or a delay to all passengers and inform them of alternative connections if the passenger has asked for such communication and provided the necessary contact details; and, the carrier must offer re-routing or a refund of the ticket price, if the delay exceeds $2 \mathrm{~h}$ in departure from a terminal (Art.19 Bus Regulation). If the carrier fails to offer the passenger those two options, the passenger shall have the right to compensation amounting to $50 \%$ of the ticket price, in addition to the reimbursement. However, no re-routing obligations have been set for coach routes of less than $250 \mathrm{~km}$ or for taxis, local trains or tramways, and the obligation does not exist for other means of transport, either, if the delay is less than the statutory time limit (Art. 23). In air transport, in case of denied boarding, delays and cancellations, the passenger must be offered information, re-routing, assistance, and compensation (Art. 7, 8 and 9 of Air Regulation). For instance, in judgment [43] the CJEU ruled that, "an air passenger who is compensated for the cancellation of a flight and who has agreed to travel on an alternative flight is entitled to compensation for a delay in the rerouting flight". The Court offered to passengers a right to compensation for each of those successive inconveniences on the grounds that passengers who have been exposed to cancellations or long delays have suffered inconvenience both in relation to the cancellation of their initially booked flight and subsequently, as a result of the long delay of their re-routing flight.

\subsection{Issues during a journey}

Some of the issues during a journey are lack of information, delays or cancellation, missed connection between legs, impossibilities and no assistance for disable people to switch to the connecting points, etc., which do not allow passengers to complete their entire multimodal journey. If so, information, compensation and re-routing obligation may arise. It would be important for passengers to know whether they themselves should ensure that they reach their final destination, or whether one of the parties of the travel chain will reroute the journey until the final destination without any extra cost. Under the re-routing obligations contained under EU Regulations is stated that the carriers must re-route the passenger only until the end of the section covered by its own mean of transport - not until the end of the entire multimodal travel. However, a MaaS provider has the obligation to reroute a passenger to the travel chain destination only if he has assumed the role of a comprehensive service provider or tour operator. For instance, a tour operator must communicate changes, and where necessary, re-route the entire travel chain (Art. 13 TPD). Otherwise, the provider of a linked travel arrangement has no communication or re-routing obligations. Based on the Eurobarometer ([23], p. 126), the majority of respondents (60\%) that requested assistance on a multimodal journey were satisfied with the assistance they received when changing modes of transport. While $34 \%$ were dissatisfied with the assistance they received.

In view of this, the following examples offer a better understanding of the issues arising during a journey in a multimodal chain. They are constructed upon the results of the Eurobarometer ([23], p. 87-88) on passenger's rights which concluded that rail transport (58\%) is the mode with the highest number of most significant disruptions, followed by air transport (33\%) of the respondents. First example: passengers have purchased a multimodal travel on the MaaS marketplace to go in Nuremberg, but at the Hamburg station it occurs that the train is delayed for $50 \mathrm{~min}$, therefore, passengers will miss a bus that leaves from Berlin to Nuremberg in $45 \mathrm{~min}$. What should the MaaS stakeholders involved in the journey do?

First, the rail company should communicate the delay and the estimated schedule, but does not have any obligation to offer re-routing to Nuremberg or a refund of the ticket price, because the delay is less than $60 \mathrm{~min}$ and its own leg ends in Berlin (Fig. 2). Second, if MaaS provider has an intermediary position does not have any obligations to re-route or compensate for the missing connection. The passenger situation corresponds to the first 3 typologies of multimodal context discussed above, when the services are purchased separately, and passengers must find out themselves how to get to the final destination. Otherwise, if MaaS provider has contractually ensured passengers to reach the final destination, then the MaaS provider must comply with it under contractual rules. 


\section{Hamburg 冒 via Berlin Nuremberg}

Fig. 2 Multimodal Passenger Transport

Second example: passengers have bought on MaaS platform multimodal tickets to go to Florence (Fig. 3) from Hamburg via Hannover, but they missed the flight (and arrived 5 or more hours later) to Florence because of a delayed train service from Hamburg to Hannover.

Here, again, passenger protection is offered only under rail Regulation. No further protection is granted under EU law to passengers for the missed connecting flight (or other means of transport), except a sue under Aquilian (extracontractual) liability in national law. However, in both examples the above distinction in section 3 between multimodal transport sold under a single contract or under separate contracts must be considered. In the latter case, passengers benefit only the protection offered under each unimodal transport Regulations. In the former case, passengers benefit higher protection in contractual terms, but here arise the issue of the law applicable to the multimodal operator's liability, unless parties have addressed it.

In other terms, under what legal framework could passengers seek compensation in case they arrived in Florence 5 or more hours late than scheduled? How should MaaS provider's liability be determined in case of single multimodal contracts (typology 5) (Fig. 3) if the failure occurs in the train-air connection? Would we measure it only under rail or air Regulation or under both of them?

In order to avoid such difficulties in establishing carrier's liability in absence of standards liability agreements, there seem to be three possible solutions, namely exclusive applicability of rail Regulation, ${ }^{7}$ coexistence of two regimes ${ }^{8}$ or exclusive applicability of air Regulation. It is the latter regime which has been proposed by the European Commission in its draft amendment of air Regulation (2013) which reads on Art. 3 that: "where a part of the journey is carried out, in accordance with a contract of carriage, by another mode of transport, the Regulation would apply for the whole journey and the

\footnotetext{
${ }^{7}$ Indeed, its applicability seems to be excluded given that compensation of the ticket price is to be paid if the journey is delayed by $60 \mathrm{~min}$ or more, determines an evident conflict with the basic principle of air Regulation pursuant to which compensation is payable in cases of delays at least 3 hours.

${ }^{8}$ This may set up the existence of a hybrid system, according to which, the operator who suffered the disruption shall bear compensation. However, this model could create confusion to consumers and need to take into account the MaaS provider position in the travel chain.
}

part of the journey carried out by another mode of transport would be considered as a connecting flight". In other terms, if a single passenger multimodal contract involves a flight segment in a rail/bus-air multimodal travel the air Regulation will apply to the whole multimodal trip regarding passengers' rights and carrier liabilities. The uniform liability system has been adopted by this proposal, the same rules apply irrespectively of the unimodal stage of transport during which damage or delay occurs. Therefore, standing to this new rule, MaaS provider's liability will be determined under air Regulation for the whole multimodal travel chain.

The main advantage of adopting a uniform liability system is its simplicity and transparency, as the applicable liability rules are predictable from the outset and do not depend on identifying the modal stage where a disruption occurs. This regime would contribute towards the harmonization of passenger's rights but might have some limits in practice. First, there is the concern that a carrier's liability exposure would increase in comparison with the current situation. If uniform rules applied irrespectively of the transport stage during which disruption occurs, a carrier would no longer be able to take advantage of potentially less burdensome liability rules which may otherwise apply to the particular mode of transport during which the problem occurs ([20], p. 26). Second, as far as subcontracting is also a main component in a single multimodal passenger contract, the recourse problem may arise. For instance, in case MaaS providers are held liable for a multimodal transport disruption, and they wish to seek recourse from the actual carrier, yet the two layers of contracts may be subject to different legal regimes and may lead to different levels of liability for the multimodal MaaS providers and the actual transport carrier. The worst scenario for the multimodal MaaS providers is that they are held liable for a larger amount than that they may regain from the actual carrier in a recourse action. This could easily occur because, as discussed above, EU transport regulations have different sets of standards for compensation of delays or cancellations. Finally, considering, for example, the whole rail/bus-air journey as if it was an air carriage may result excessive to the air carrier (or MaaS providers) even in circumstances in which they do no maintain any de facto control over the passenger (i.e., transfers between the airport to the railway/bus station; rail/bus journey; eventual delay or cancellation of the train/bus, etc). Therefore, the amendment of air 


\section{Hamburg 冒 via Hannover $九$ Florence}

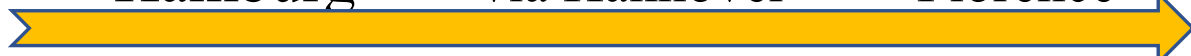

Fig. 3 Multimodal Passenger Transport

Regulation requires, consequently, also an amend of rail/ bus Regulation to the extent that harmonize multimodal passenger rights in train/bus-air journeys. In any case, according to Brunagel et al, ([21], p. 115) between various policy package considered to protect passenger when travelling multimodal, the proposal on air Regulation would yield the best outcome for passengers in terms of compensation by creating a dedicated regulation on multimodal transport. Yet, the market share which can be reached for single contracts - offering the best protection to passengers travelling multimodal - remains limited, as the revision of air Regulation might deter the industry to develop such products. The EU's Commission 2020 work program has included the above proposal and the new rail regulation proposal [44] as its priory pending proposals.

\subsection{Complaints and compensation}

The term 'secondary rights' is used to identify those rights of passengers which are ascribable to the legitimate expectation of availing oneself of efficient service and being refunded when this does not happen. Typical examples are contractual and/or extra contractual carrier's liability ([41], p. 139). According to the Eurobarometer ([23], p. 99) while less than four in ten (37\%) of the people who experienced travel disruptions are satisfied with the way the transport company informed them about complaints procedures, the majority of respondents (55\%) were dissatisfied; and the majority (55\%) of respondents who made a complaint are satisfied with the way their complaint was handled by the transport company (2020, p. 106). In order to get compensation, after a transport disruption in a travel chain, passengers must lodge a complaint. According to general principles, the complaint must be submitted to one's own contracting partner in order to be valid. Indeed, two-thirds of respondents in the Eurobarometer ([23], p. 91) would complain to the transport company in the event of a serious travel disruption, all modes combined. Whenever the MaaS provider is the direct contracting partner of the passenger and responsible for the performance of the passenger transport service providers, it uses as it were for its own. According to Art. 27 of rail Regulation, passengers may submit a complaint to any railway undertaking involved. While the bus Regulation states that if a passenger wants to make a complaint to the carrier, they must submit it within 3 months from the date on which the regular service was performed or when a regular service should have been performed, after which the carrier must inform the passenger of the status of the complaint (Art. 27). Therefore, the rules depend on whether the passengers are consumers or business travellers, what is the role of the MaaS provider and which mode of transport is concerned. According to FICORA [34], on MaaS ecosystem, in order to improve the options of a consumer to make a complaint, consumers could have a "one-stop shop" for all complaints and not have their rights compromised simply because they selected the wrong one of the travel chain parties to submit a complaint to.

In the event of death, bodily injury, cancellation or significant delays the EU passenger rules provide for mandatory compensation and assistance schemes specific to each mode of transport. In air Regulation, passengers' rights are protected by imposing a financial compensation based on the distance of the flight and the amount of delay incurred at the final destination (Art. 7). On the other hand, art. 3 of Regulation (EC) NO $889 / 2002$ on air carrier liability in the event of accidents establishes the carrier's liability 'in case of death or bodily injury took place on board the aircraft or in the course of any of the operations of embarking or disembarking'. In case 'HQ and Others v Aegean Airlines' (2019) the CJEU stated that 'passengers who have the right to hold their tour organiser liable for reimbursement of the cost of their air tickets, cannot also claim reimbursement of the cost of those tickets from the air carrier.' Such a cumulative right to reimbursement would lead to an unjustified overcompensation of passengers to the detriment of the air carrier. While in 'CS and Others v České aerolinie' (2019) the CJEU found liable the air carrier that performed the first leg of a connecting flights that are the subject of a single reservation to pay compensation to passengers who suffered a long delay in the arrival of the second flight. In rail transport, the compensation for delays or cancellations set out in Art. 17, is between 25 and $50 \%$ of the ticket price. The new proposal on rail Regulation provide that when a train is severely delayed, passengers could either request a refund of the full ticket price or continue the journey and ask for a partial reimbursement. The proposal backs the idea of increasing compensation, depending on the length of the delay (Art. 16/17). The right of passengers 
travelling by bus or coach can be enforced in fully on regular services of over $250 \mathrm{~km}$ where passengers board or alight in the territory of Member Sate. According to Art. 7 of this Regulation, 'the carrier will be liable in accordance with the applicable national law, for personal injury to or death of a passenger arising out of the use of bus or coach'.

It's important to bear in mind that for all means of transportation limitation on carrier's liability are provided. An obstacle to compensating for the damage caused by the disruption of the travel chain may be the requirement for foreseeability, because a carrier may not be at all aware of the fact that the passenger transport service is a link in a long travel chain. However, if a MaaS provider has assumed a guarantee role towards the passenger, he may be liable for damage caused by missed connections because they have entered into a contract on the completion of the entire travel chain. If the passengers fail to reach the intended destination, the service provided by the MaaS provider fails to meet the contract, and there is a fault in the service. The passenger's right to remedy is determined under general contractual law principles. If the MaaS provider is in the position of an intermediary, it is not liable for damage caused by disruptions of a passenger carrier. Exception may be if the damage is due to his acting without due care in its intermediary task. For instance, if the MaaS provider has allowed for such a short connecting time that the travel chain would fail even in the case of a slight delay. Interestingly, in judgment 'Dirk Harms and Others v Vueling Airlines SA' (2018) the CJEU found that in case of cancellation of a flight, the airline company must also reimburse commissions collected by intermediaries when tickets are bought, as long as it was aware of them. Consequently, companies may have an action of redress upon MaaS provider whenever acting as an intermediary.

\section{Conclusion}

MaaS is improving user's experience by offering a digital mobility marketplace and tailormade trips. In view of this, the main aim of this paper was to assess how does MaaS multimodality fit under the current EU transport law which is based upon the principle of unimodality. The analysis has identified situations where passengers travelling under multimodal transport did not benefit from any EU transport law protection. In particular, in the absence of a contractual agreement, liability relations between parties may remain unclear, harming passengers' rights. Stakeholders involved in a multimodal chain must be aware of their role and position and should agree with who provides what to the passenger for successful trips. Moreover, in order to harmonize the passenger rights in the EU, and to avoid Regulations' clash, it's necessary to amend all the transport Regulations from a multimodal perspective. Yet, before taking that initiative, first the EU should ensure a legal framework on delivering wide integrated ticketing and payment systems, which is a precondition for the rise of MaaS concept. An important step in that direction is the EU Regulation (2017/1926) with regard to the provision of EU-wide multimodal travel information service (MITS), which provided that all Member States must open National Access Points (NAP's) to facilitate access, easy exchange and reuse of transport statistics and dynamic data. Unfortunately, this Regulation does not provide the right to access the payment data services of transport operators, as granted by the Finnish Transport Service Act (320/2017) and French Mobility Law of Orientation (2019/1428) [45]. These national rules lay down provisions for the technical interoperability of ticketing systems by requiring all public transport providers to open their single or seasonal ticket APIs for third-party resale and use, such as MaaS providers. Yet, the MITS Regulation has included provisions regarding open data for pricing and how to order (Søren [46]) from a mobility platform. In practical terms, starting from December 2020 any MaaS and other mobility platform may exhibit to its user how much transport providers tickets cost and also provide a direct link to the booking page of the respective transport provider where the users can, then, purchase tickets. However, in order to realize the Finnish and French models, a new EU Regulation/Directive is required to provide direct access also to the payment data services of transport operators from MaaS platform providers. Indeed, in its recent document entitled ' A european strategy for data' [47] the EU Commission ackowledged the issue of data access on mobility sector and proposed that it will review/amend the Directive on Intelligent Transport Systems (2010/40/EU) including its delegated Regulation (2017/1926) to further contribute to data availability, reuse and interoperability (both in 2021) and establish a stronger coordination mechanism to federate the NAP's established under the ITS Directive. In other terms, the EU will provide a normative precondition for the facilitation of a new e-ticketing system and the right to access mobility data under specific circumstances where access to mobility data should be made compulsory and under specific conditions (i.e., fair, transparent, reasonable, proportionate and/or non-discriminatory condition, etc.). However, it's unclear how much it is intended to force business to share data and what kind of data possible obligation would cover. From a user's perspective, the benefits of that would be an easy access to various means of transport around EU and the chance to have roaming in mobility (similar to telecommunication sector), cutting mobility costs. For instance, once users have a MaaS app 
or have bought a MaaS mobility package in Helsinki and they are in vacation in Vienna, the Finnish Whim app currently offers the possibility not only to buy Vienna's mobility means, but also to use the same mobility package acquired in Helsinki. The purpose is to make a multimodal transport more attractive for users and to promote a more efficient use of existing infrastructure and services. The combined selling of various tickets from different operators would solve some of the problems relating to the carrier's liability.

\section{Acknowledgements}

The author gratefully thanks Prof. Federico Costantini (University of Udine) who first introduced him to the MaaS concept and Prof. Hans Heinrich Trute (University of Hamburg) who agreed to supervise his Ph.D MaaS project. All mistakes and errors are these of the author.

\section{Case law}

Sabrina Wathelet v. Garage Bietheres \& Fils SPRL, C-149/15; EU:C:2016:840.

Elite Taxi v. UberPop, C-434/15, ECLI:EU:C:2017:981.

Dirk Harms and Others v Vueling Airlines SA, C-601/17; ECLI:EU:C:2018:702.

HQ and Others v Aegean Airlines, C-163/18; ECLI:EU:C:2019:585.

Airbnb vs ATHOP, Case C-390/19 ECLI:EU:C:2019:1112.

$A$ and Others v Finnair Oyj C-832/18 ECLI:EU:C:2020:204.

\section{Legislation}

Regulation (EC) NO 261/2004 establishing common rules on compensation and assistance to passengers in the event of denied boarding and of cancellation or long delay of flights, and repealing Regulation (EEC) No 295/ 91.

Regulation (EC) No 1371/2007 of the European Parliament and of the Council of 23 October 2007 on rail passengers' rights and obligations. Regulation (EU) No 181/2011 of the European Parliament and of the Council of 16 February 2011 concerning the rights of passengers in bus and coach transport and amending Regulation (EC) No 2006/2004 Text with EEA relevance.

Directive (EU) 2015/2302 of the European Parliament and of the Council of 25 November 2015 on package travel and linked travel arrangements, amending Regulation (EC) No 2006/2004 and Directive 2011/83/EU of the European Parliament and of the Council and repealing Council Directive 90/ 314/EEC

\section{Author's contributions}

The author(s) read and approved the final manuscript.

\section{Funding}

The research of MaaS concept was funded by the University of Hamburg, Faculty of Law, AMBSL Germany. The fee for the publication of this paper is covered by the IcoMaaS 2019 Conference, University of Tampere, Tampere Finland.

\section{Availability of data and materials}

Some of the data and the materials could be accessed through the links the author has provided in the references. While the rest of them are books which may be accessed searching their title.

\section{Competing interests}

Not applicable.

Received: 15 April 2020 Accepted: 28 September 2020

Published online: 10 November 2020

\section{References}

1. Shaheen, S., \& Cohen, A. (2017). Smartphone app evolution and early understanding from a multimodal app user survey. In G. Meyer, \& S. Shaheen (Eds.), Disrupting mobility. Springer.

2. Aguilera, A. (2018). Smartphone and individual travel behaviour. In A. Aguilera, \& V. Boutile (Eds.), Urban mobility and the smartphone. Elsevier.
3. Dinning, M., \& Weisenberger, T. (2017). Multimodal transportation payments convergence-Key to mobility. In G. Meyer, \& S. Shaheen (Eds.), Disrupting mobility. Springer.

4. Montero, J. (2019). Regulating transport platforms: The case of carpooling in Europe. In M. Finger, \& M. Audoin (Eds.), The governance of smart transportation systems. Springer.

5. Smith, G., Sarasini, S., Karlsson, M., Mukhtar-Landgren, D., \& Jana Sochor, J. (2019). Governing MaaS: Insights from Sweden and Finland. In M. Finger, \& M. Audoin (Eds.), The governance of smart transportation systems. Springer.

6. Hietanen, S. (2014). "Mobility as a Service" - The new transport model? In ITS \& Transport Management Supplement. Eurotransport, 12(2), 2-4.

7. Utriainen, R., \& Pöllänen, M. (2017). Review on mobility as a service in scientific literature, in ICoMaaS. Available at. https://tutcris.tut.fi/portal/files/13459464/ IcoMaaS_Utriainen_P_II_nen.pdf. Accessed 12 June2020.

8. Arias-Molinares, D., \& García-Palomares, J. C. (2020). The Ws of MaaS: Understanding mobility as a service from a literature review. in IATSS Research.

9. House of Commons, Transport Committee (2018). Mobility as a service. https://www.parliament.uk/business/committees/committees-a-z/commonsselect/transport-committee/inquiries/parliament-2017/mobility-as-a-service-1 7-19/. Accessed 1 Dec 2018.

10. Kamargianni, M., \& Matyas, M. (2017). The business ecosystem of mobility-as-a service. Washington DC: Presented at the 96th transportation research board annual meeting 8-12 January 2017.

11. Smith, G., Sochor, J., \& Karlsson, I. C. M. (2018). Mobility as a service: Development scenarios and implications for public transport. Research in Transportation Economics, 69, 592-599 https://doi.org/10.1016/j.retrec.2018. 04.001.

12. Smith, G. (2020). Making mobility-as-a-service: Towards governance principles and pathways. In Chalmers, industrial and materials science, design and human factors.

13. König, D., et al. (2016). Deliverable 3: Business and operator models for MaaS. https://www.vtt.fi/sites/maasifie/Publishinglmages/results/cedr_mobility_ MAASiFiE_deliverable_3_revised_final.pdf. Accessed 1 Dec 2019.

14. Lundqvist, B., \& Murati, E. (2020). Collaborative platforms and data pools for smart urban societies and mobility as a service (MaaS) from a competition law perspective. In M. Finck et al. (Eds.), Smart Urban Mobility Law, Regulation, and Policy. Springer.

15. Heinen, E. (2018). Are multimodals more likely to change their travel behaviour? A cross-sectional analysis to explore the theoretical link between multimodalilty and the intention to change mode choice. Transportation Research Part F: Traffic Psychology and Behaviour, 56, 200-214.

16. European Commission (2016a). A European strategy for low-emission mobility, (p. 501). COM.

17. European Commission (2016b). Interpretative guidelines on regulation (EC) no 261/2004. COM (C 214/2016)

18. European Commission (2019). The European green Deal, (p. 640). COM.

19. Finger, M., \& Audouin, M. (2019). Introduction. In M. Finger, \& M. Audoin (Eds.), The governance of smart transportation systems. Springer.

20. Hoeks, M. (2010). Multimodal transport law: The law applicable to the multimodal contract for the carriage of goods. Wolters Kluwer.

21. Brunagel, M., et al. (2019). Exploratory study on passenger rights in the multimodal context. https://op.europa.eu/en/publication-detail/-/publication/ f176da6f-d9ca-11e9-9c4e-01aa75ed71a1. Accessed 1 July 2019.

22. Trimarchi, A. (2019). Intermodal air-rail agreements: Legal aspects and considerations. Air \& Space Law, 44(1), 27-44.

23. European Commission Special Eurobarometer 485 (2020). Passenger rights. Report EN MI-02-19-685-EN-N 978-92-76-09827-0. https://doi.org/10.2832/ 645239.

24. Sochor, J., et al. (2017). A topological approach to MaaS: A proposed tool for understanding requirements and effects, and for aiding the integration of social goals. ICOMaaS1, 93.

25. Hazan, J., et al. (2019). Seeking perpetual motion with mobility as a service. https://www.bcg.com/publications/2019/seeking-perpetual-motion-mobilityas-service.aspx. Accessed 11 Mar 2019.

26. Goodall, W., et al. (2017). The rise of mobility as a service, reshaping how urbanities get around. https://www2.deloitte.com/us/en/insights/deloittereview/issue-20/smart-transportation-technology-mobility-as-a-service.html. Accessed 1 Mar 2020.

27. European Commission (2013). Proposal amending Regulation (EC) No 261/ 2004 establishing common rules on compensation and assistance to 
passengers in the event of denied boarding and of cancellation or long delay of flights and Regulation (EC) No 2027/97 on air carrier liability in respect of the carriage of passengers and their baggage. COM/2013/0130 final.

28. Vasilj, A., \& Erceg, B. (2018). Current affairs in passenger rights protection in the EU. In T. Petrašević, \& D. Duić (Eds.), EU law in context - Adjustment to membership and challenges of the enlargement. Faculty of Law, Josip Juraj Strossmayer University of Osijek.

29. European Court Auditors (2018). Passenger rights are comprehensive, but passengers still need to fight for them. Special report no 30.

30. Marin, J. (2018). Passengers' rights and consumer protection. In J. Marin et al. (Eds.), Uber brave new service or unfair competition/consumer e passenger protection. Springer.

31. European Commission (2011). A European vision for passengers: Communication on passenger rights in all transport modes, (p. 898). COM.

32. European Commission (2017). Interpretative quidelines on regulation (EC) no 1371/2007 on rail passengers' rights and obligations. COM (2015/C 220/01).

33. Gautier, P. (2017). How make sure passengers rights are better protected in multimodal journey. https://www.beuc.eu/publications/beuc-x-2017-057_ pga_beuc_position_paper_pr_in_multimodal_journeys.pdf. Accessed 4 Dec 2019.

34. FICORA (2018). Lippu project report on contractual practices for travel chains defined in the Act on Transport Services. https://www.traficom.fi/sites/default/ files/media/file/Contractual\%20practices\%20for\%20travel\%20chains\%2 Odefined\%20in\%20the\%20Act\%20on\%20Transport\%20Services\%20.pdf . Accessed 1 Oct 2019.

35. Rey, T. (2017). Innovation brief on mobility as a service. Available at http:// sumpnetwork.eu/fileadmin/user_upload/Innovation_Brief_Mobility_as_a_ Service_22_08_2017_web.pdf. Accessed 22 May 2020.

36. Pinar, A. (2019). Online platforms, agency, and competition law: Mind the gap (July 12, 2019). Fordham International Law Journal 209, 43(2) Available at SSRN: https://ssrn.com/abstract=3419067.

37. Dittmar and Indrenius (2017) Preparation of a code of conduct for a mobility service network consumer and data protection and liability issues. Consumer and data protection and liability issues. https://www.traficom.fi/sites/default/ files/media/file/Preparation\%20of\%20a\%20code\%20of\%20conduct\%20for\%2 0a\%20mobility\%20service\%20network.pdf. Accessed 1 June 2019.

38. Case law Sabrina Wathelet v. Garage Bietheres \& Fils SPR L, C-149/15; EU:C: 2016:840.

39. Straetmans, G. (2019). Information obligations and disinformation of consumers. In G. G. Straetmans (Ed.), Information obligations and disinformation of consumers. Springer.

40. Ranchordás, S. (2020). Smart Mobility, Transport Poverty and the Legal Framework of Inclusive Mobility. In M. Finck, M. Lamping, V. Moscon, \& H. Richter (Eds.), Smart Urban Mobility. MPI Studies on Intellectual Property and Competition Law, (vol. 29). Berlin, Heidelberg: Springer https://doi.org/10. 1007/978-3-662-61920-9_4

41. Pozzo, F. R. D. (2015). EU legal framework for safeguarding air passenger rights. Springer.

42. Murati, E., \& Hënkoja, M. (2019). Location data privacy on MaaS under GDPR. Issue 2019/2, p. 115-136, EJPLT.

43. A and Others v Finnair Oyj C-832/18 ECLI:EU:C:2020:204

44. European Commission Work Programme (2020). A union that strives for more' COM (2020) 37 final.

45. Urban Mobility (2020). Your guide to the French mobility orientation law. Available at https://urbanmobilitycompany.com/content/daily/your-guideto-the-french-mobility-orientation-law. Accessed 2 Apr 2020.

46. Sørensen, S. (2020). Open mobility data in the EU entering level 2. Available at http://sfmcon.dk/wp-content/uploads/sites/13160/2020/05/IntroducingMMTIS-level-2-v1.0.pdf. Accessed 19 May 2019.

47. European Commission (2020). A European strategy for data. COM (2020) 66 final.

\section{Publisher's Note}

Springer Nature remains neutral with regard to jurisdictional claims in published maps and institutional affiliations.

\section{Submit your manuscript to a SpringerOpen ${ }^{\circ}$ journal and benefit from:}

- Convenient online submission

- Rigorous peer review

- Open access: articles freely available online

- High visibility within the field

- Retaining the copyright to your article

Submit your next manuscript at $\boldsymbol{\nabla}$ springeropen.com 